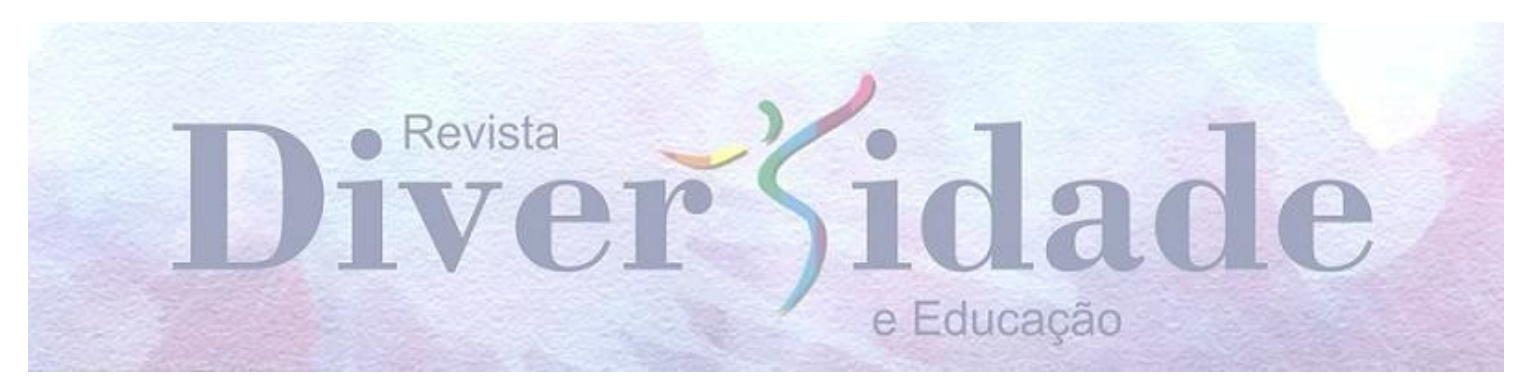

\title{
CORPO, GÊNERO, ENVELHECIMENTO E CULTURA VISUAL: A DANÇA ABRINDO AS FRONTEIRAS ENTRE O POSSÍVEL E O INIMAGINÁVEL
}

\author{
CUERPO, GÉNERO, ENVEJECIMIENTO Y CULTURA VISUAL: \\ DANZA QUE ABRE LOS LÍMITES ENTRE LO POSIBLE Y LO \\ INIMAGINABLE
}

\author{
BODY, GENDER, AGING AND VISUAL CULTURE: DANCE OPENING \\ THE BOUNDARIES BETWEEN THE POSSIBLE AND THE UNIMAGINABLE
}

\author{
Anderson José de Oliveira1 \\ Neil Franco 2 \\ Nayara Rios Cunha Salvador3
}

\section{RESUMO}

O presente artigo discute diferentes temas através de uma apresentação do programa Got Talent no qual uma senhora de aproximadamente 80 anos faz uma performance acrobática com um dançarino mais jovem. Analisando estas imagens, percebe-se o estranhamento frente a um casal tão peculiar. Tal aspecto foi observado por meio das expressões faciais da plateia e jurados e também pelas falas destes últimos, antes e posteriormente à apresentação do referido casal. Através deste material foram feitas discussões relacionadas a gênero, corpo e envelhecimento, problematizando os limites impostos pela sociedade para o corpo de uma mulher idosa. Para a realização deste ensaio utilizamos de metodologia qualitativa com a correlação de fontes midiáticas e bibliográficas em uma perspectiva pós-crítica. Percebemos que a performance desta senhora nos permite afirmar que pensar o corpo na e pela cultura é um caminho para desnaturalizá-lo e entendê-lo como um processo cultural e histórico.

PALAVRAS-CHAVE: Dança. Corpo. Envelhecimento. Gênero 


\title{
RESUMEN
}

El presente articulo analiza diferentes temas a través de una presentación del programa Got Talent en el que una mujer anciana realiza una actuación con un bailarín más joven. Analizando estas imágenes, se nota la extrañeza hacia la pareja. Este aspecto se observó por las expresiones faciales de la audiencia y del jurado y también a través de los discursos de este último antes y después de la presentación. A través de este material, se realizaron discusiones sobre género, cuerpo y envejecimiento, cuestionando los límites impuestos por la sociedad para el cuerpo de una mujer mayor. Para llevar a cabo este ensayo, utilizamos metodología cualitativa y correlación de medios y fuentes bibliográficas com una mirada postcrítica. Concluimos que el desempeño de esta dama nos permite afirmar que pensar el cuerpo a través de la cultura es una forma de desnaturalizarlo y entenderlo como um proceso histórico

PALABRAS CLAVE: Danza. Cuerpo. Envejecimiento. Género.

\begin{abstract}
This article analyzes different topics through a presentation of Got Talent program in which an elderly woman performs with a younger dancer. Analyzing these images, leads us to realize the strangeness towards the couple. This aspect was observed by the facial expressions of the audience and the jury and also through the latter's speeches before and after the presentation. Through this material, discussions on gender, body and aging were held, questioning the limits imposed by society for the body of an older woman. To carry out this text, we used qualitative methodology and correlation of media and bibliographic sources with a post-critical perspective. We conclude that the performance of this lady allows us to affirm that thinking about the body through culture is a way of denaturing it and understanding it as a historical process.
\end{abstract}

KEYWORDS: Dance. Body. Aging. Genre.

\section{Introdução}

$\mathrm{Na}$ atualidade, com a popularização da internet e maior acesso a aparelhos como celulares e tablets, imagens rodam o mundo em questão de minutos, talvez segundos. Segundo Maria Emilia Sardelich (2006), na contemporaneidade praticamente tudo do que se sabe vinculado ao conhecimento produzido chega às pessoas via Tecnologias da Informação e Comunicação e essas edificam imagens do mundo.

Nômades nas próprias residências, as pessoas capturam imagens, por diversas vezes sem modelo, cópias de cópias, no entrecruzar de diversas significações. Imagens recreativas e publicitárias, que informam sobre o que vestir, comer ou pensar.

Com uso constante de aparelhos eletrônicos, crianças/adolescentes têm contato com um mundo de limites ampliados para além de sua realidade física, no qual a 
curiosidade em explorar novos contextos se apresenta e é saciada em telas de diferentes tamanhos. Diferentes imagens se apresentam de diferentes formas.

Assim, com o intuito de trazer elementos que podem ser usados como instrumentos pedagógicos para a problematização de conceitos relacionados à discussão de gênero, corpo, dança e envelhecimento, serão feitas algumas considerações a respeito de uma apresentação de dança do programa Got Talent, realizada na Grã-Bretanha, por uma senhora de 80 anos com um parceiro bem mais jovem que ela.

Tal apresentação nos instigou aos seguintes questionamentos que norteiam este ensaio: Se o corpo traz na estrutura sinais que o classificam, qual o valor das marcas produzidas pelo tempo? "Quanto valem" as rugas? "Quanto valem" os cabelos brancos? "Quanto vale" manifestar em seu corpo as marcas do envelhecimento proporcionado pelo passar dos anos? Em que medida o corpo, o gênero e a questão geracional podem desencadear novas formas de se pensar as relações entre homens e mulheres pela via da dança?

Para responder a essas questões o presente ensaio se sustenta em metodologia qualitativa e na correlação de fontes midiáticas e bibliográficas que possibilitam a discussão do corpo numa perspectiva pós-crítica. Neste sentido: “Ocupamo-nos do já conhecido para suspender significados, interrogar os textos, encontrar outros caminhos, rever e problematizar os saberes produzidos e os percursos trilhados por outros." (PARAÍSO, 2012, p. 25). Nessa linha, o corpo feminino idoso e a dança são para onde direcionamos nosso olhar e reflexões.

\section{Conduzida por um jovem, entra em cena a velha senhora...}

Antes de falar especificamente a respeito dessa performance, convém salientar que, segundo Irene Tourinho (2011), entender a experiência de ver e ser visto não limita-se apenas a um olhar ou perspectiva. O significado atribuído às imagens constroem-se através das limitações, cegueiras e circunstâncias constituintes dos sujeitos como também se constroem através das diferentes maneiras através das quais as imagens podem ser reconstruídas, colocadas em circulação e recepcionadas.

Maria Emilia Sardelich (2006) dialogando com Mirzoeff (2003) afirma que a visualização exprime o mundo contemporâneo. Isso, no entanto, não quer dizer que conheçamos o que observamos. A linha que se traça entre a diversidade do que é visto 
na cultura contemporânea e a capacidade para examinar esta observação gera a necessidade de transformar a cultura visual em um campo de estudo.

Tourinho (2011) diz que a cultura visual possui apreço pelos fenômenos visuais da atualidade "na utilização social, afetiva e político-ideológica das imagens e nas práticas culturais e educativas que emergem do uso dessas imagens." (TOURINHO 2011, p. 12) Ao partir dessa perspectiva a cultura visual entende que a percepção é também uma forma de interpretar, sendo assim uma forma de produzir significados, possuindo íntima relação com o ponto de vista do observador/espectador no que se refere à classe, etnia, faixa etária dentre outras experiências socioculturais.

As imagens "[...] como entidades visuais concretas, produzem impacto sobre nossas vidas podendo ser vistas como expressões do contexto cultural que nos cerca e como uma forma particular de vermos e expressarmos o mundo." (IUNG; PORTUGAL, 2012, p. 28).

Segundo Raimundo Martins (2011), em nosso cotidiano se fazem presentes mídias conhecidas como a fotografia, mídias tradicionais como pintura e novas mídias como a web. Juntos estes artefatos disseminam comportamentos e valores que ultrapassam os limites entre público e privado, provocando não só a invasão como também a evasão da privacidade que é divulgada através de diferentes formas e por diferentes mídias. A interpretação de objetos e imagens congrega concomitantemente a memória visual e também a memória social construída pelos sujeitos que interpretam. Assim, ao buscar entender o sentido simbólico das imagens, as pessoas sofrem influência do imaginário dos espaços sociais frequentados por elas, pelos lugares onde vivem ou que habitam.

Neste sentido, compreende-se o corpo como uma construção discursiva produzida nas relações de saber e poder. Não há, dessa maneira, um corpo natural, anterior à cultura e às relações e trocas simbólicas. Segundo Kleber Padro Filho e Sabrina Trisotto (2008, p. 116), o corpo é resultado de diversos investimentos, enunciações e saberes. "Sua própria natureza é construída".

No mesmo sentido, Maria Eduarda Guimarães (2005) relata que a construção desse corpo não natural passa pela noção de inscrição do pertencimento, de forma que corpo, identidade e cultura se apoiam e se retroalimentam. A expressão dessa noção de pertencimento ocorre através do uso do corpo, por meio de gestos e práticas, como tatuagens, piercings e body building. O corpo, então torna-se território sobre o qual recai o poder, conforme anuncia Foucault (2008, p. 118): "esses métodos que permitem 
o controle minucioso das operações do corpo, que realizam a sujeição constante de suas forças e lhes impõem uma relação de docilidade-utilidade, são o que podemos chamar 'as disciplinas'."

Seguindo o rastro de Foucault (2008), percebe-se o disciplinamento do corpo através de determinados contextos nos quais a imagem de um tipo de estereótipo corporal é perseguido. Assim, o corpo "malhado" é almejado na academia de musculação, por exemplo. Para alguns vale também se submeter a inúmeras plásticas faciais para esconder as marcas provocadas pelo passar dos anos. Modelos ideais são divulgados, almejados, invejados e perseguidos, como se houvesse um padrão corporal certo para cada atividade humana.

Tal busca justifica-se nos dizeres de Guacira Louro (2003), para quem a posição dos sujeitos dentro de uma determinada cultura possui relação direta com e como os seus corpos se mostram. No decorrer do tempo as pessoas têm sido classificadas e ordenadas devido à aparência de seus corpos. Todos os aspectos e cada detalhe dos corpos passam a ser significados culturalmente, de modo que o que importa em um corpo, pode não importar em outro, a depender do local, do momento histórico e cultural e da sociedade que estes corpos ocupam. O que torna as experiências corporais mais aproximadas é o fato de que em todas as sociedades e culturas, os corpos que carregam marcas valorizadas (por aquela sociedade/cultura) são aqueles que recebem mais valor e possibilidade de destaque. Reproduzindo a expressão cunhada por Judith Butler (1993): são "corpos que importam".

Uma dessas marcas trazidas pelos corpos é o envelhecimento. O corpo das pessoas idosas possuem traços que as definem. Muitas vezes estas marcas levam à compreensão de uma série de limitações relacionadas ao envelhecimento.

Anderson de Oliveira et al (2003), através de uma pesquisa que analisou a percepção das pessoas em relação ao envelhecimento, apontaram que a maioria dos sujeitos entrevistados entendiam a fase da vida em que se encontravam as pessoas idosas como símbolo de "perdas e privações". Enxergavam a pessoa idosa como aquela que, ao longo dos tempos, vê atenuadas suas capacidades, habilidades, percepções.

Se a esse estereótipo acrescentamos um gênero feminino, considerando que a construção identitária se dá de forma interseccionada, temos mais algumas questões a serem consideradas. 
Conforme verifica-se, as relações de gênero, como construções sociais de formas de dominação e subordinação, têm resultado, historicamente, em experiências e trajetórias sociais diferenciadas para homem e para mulher, particularmente para as mulheres idosas de hoje, as quais vivenciaram a expectativa obrigatória de uma "feminilidade" marcada pela obediência, pelo conformismo e pelas desigualdades, além de uma apropriação social do seu corpo expresso no controle familiar e na medicalização das funções reprodutivas (FERNANDES, 2009, p. 165).

Ainda com relação às construções sobre o que é considerado masculino ou feminino, temos as construções da relação do "eu" com o corpo, que se dão de forma diferente a depender do gênero, de modo que, segundo Junia Vilhena e Joana Novaes (2009), o corpo feminino, ao longo dos anos, foi pensado e compreendido como insuficiente, uma vez que a cultura falocêntrica induzia à comparação deste corpo com o corpo masculino. Esta "falta", era entretanto, suprida pelo fato de a mulher deter o "poder" da maternidade, o que a identificou como "geradora da vida" desde os primórdios da civilização.

A identificação do corpo feminino com a capacidade de gerar outro ser, entretanto, não diminui as representações negativas com relação a ele. Compreendido como ameaçador e misterioso, este corpo passou a ser domesticado, associado exclusivamente à maternidade e à procriação. Neste sentido, a mulher que buscava experimentar outras formas de viver o corpo, era compreendida como histérica ou psicótica (FURTADO, 2001).

Uma vez que o corpo feminino é, ainda hoje, relacionado à maternidade, percebe-se que o amadurecimento deste corpo e a perda da capacidade de reprodução alinhada à menopausa, trazem algumas representações acerca da capacidade da mulher, de sua feminilidade e de sua sexualidade. A mulher cujo corpo amadureceu passa a ser vista como inservível aos olhos da sociedade, fazendo com que ela busque, de diversos modos, evitar o envelhecimento ou mascará-lo (VILHENA; NOVAES, 2009).

Outro aspecto importante acerca do corpo suscitado pelas autoras supracitadas reside no fato de que ele nunca é compreendido de forma integral em um "primeiro olhar" pelos dispositivos culturais:

Uma vez que o corpo nunca é totalmente apreendido pelos dispositivos culturais, que possibilitem sua submissão completa às expectativas sociais, a "feiúra" ou o "estranho", muitas vezes poderão ser tomados como uma mensagem, cuja força reside, justamente, na 
sua surpreendente apresentação (VILHENA E NOVAES, 2009, p. 94).

O conceito de representação assume, nesse contexto, importante significado. Segundo Stuart Hall, representação diz respeito à utilização da linguagem para, de maneira clara, manifestar algo sobre o mundo ou representá-lo. Ela é fundamental no processo de construção e compartilhamento de significados dentro de um grupo localizado em determinada cultura. Percebemos que certos símbolos possuem sentido no contexto em que estão inseridos. Assim, por exemplo, uma medalha olímpica apesar de ser apenas um amontoado de metais em um formato circular, representa para o atleta que conquistou tal honraria, o esforço, a dor, a abnegação da vida pessoal para a realização de um sonho. Segundo Silva (2005, p. 103) "a representação é sempre inscrição, é sempre uma construção linguística e discursiva dependente de relações de poder."

As reflexões acima ganham expressão quando vemos adentrar no palco de um programa de talentos denominado Got Talent um casal em que um dos/as integrantes era uma senhora idosa.

Got Talent é um programa de televisão da ITV. De sua sede na Grã-Bretanha foi adaptado para diferentes países como Canadá, Portugal, Espanha e Coréia. O objetivo desse show de talentos é descobrir artistas em diferentes modalidades de atuação como: dança, música, comédia etc. Segundo o site wikipedia tal programa ganhou a atenção do público da internet devido à Susan Boyle. Esta cantora se apresentou na terceira edição do programa em 2009 e surpreendeu a todos com sua bela voz.

Diferentes personagens se apesentam com as mais variadas performances. Quando estas não agradam os jurados, eles tocam uma companhia que se for apertada por todos, o artista é eliminado. Não é incomum nestes programas, tanto os da Grã Bretanha quanto em outros países, que os participantes sejam julgados pela sua aparência. A própria Susan Boyle4, que popularizou o programa, foi julgada por sua forma de se portar e vestir. Às vezes os jurados debocham dos candidatos. Simon Cowell, também criador do programa é o jurado mais "mal humorado". É rotineiro, durante as audições ele demonstrar expressões faciais e comentários criticando e reprovando os candidatos que se apresentam. 
Essas duas últimas características descritas se fizeram presente na apresentação que foi objeto de análise do presente trabalho. Uma senhora de 80 anos adentrar com um parceiro bem mais jovem do que ela representava a fragilidade e talvez a incapacidade de alguém que leva em seu corpo a marca do tempo. Assim que os dançarinos entraram ouviram um comentário em tom de deboche por um dos jurados. Este indagou qual era o tipo de relação que o casal possuía, o que levou a plateia a risos. Logo iniciado o pas de deux, a campainha para eliminação foi acionada. Pode ser observada em outras apresentações de 2014, ano da referida performance, que tal reação inicial dos jurados não se deu da mesma forma. Os calouros foram tratados sem qualquer espanto causado devido a sua aparência.

O fato dessa "senhora" pleitear competir nesse programa com algo no qual supostamente seu corpo não poderia obter um "rendimento" satisfatório causou aparentemente nos jurados certa descrença.

\section{Algumas reflexões acerca da performance no programa Got Talent}

Pautados na compreensão do gênero como construção social e cultural interseccionada por diversos fatores, entre eles pelo fator geracional, conforme anteriormente explicitado, apresentamos análises imagéticas correlacionadas com as fontes teóricas utilizadas neste trabalho, que nos permitem entender que a compreensão sobre "os corpos possíveis" é construída em meio a relações de saber e poder, em que alguns padrões e normas socialmente impostas delimitam os corpos possíveis e o que esses corpos podem ou não executar e mostrar em público (BUTLER, 1993; LOURO, 1997). 
$1^{\text {a }}$ Imagem retirada do vídeo objeto deste estudo.

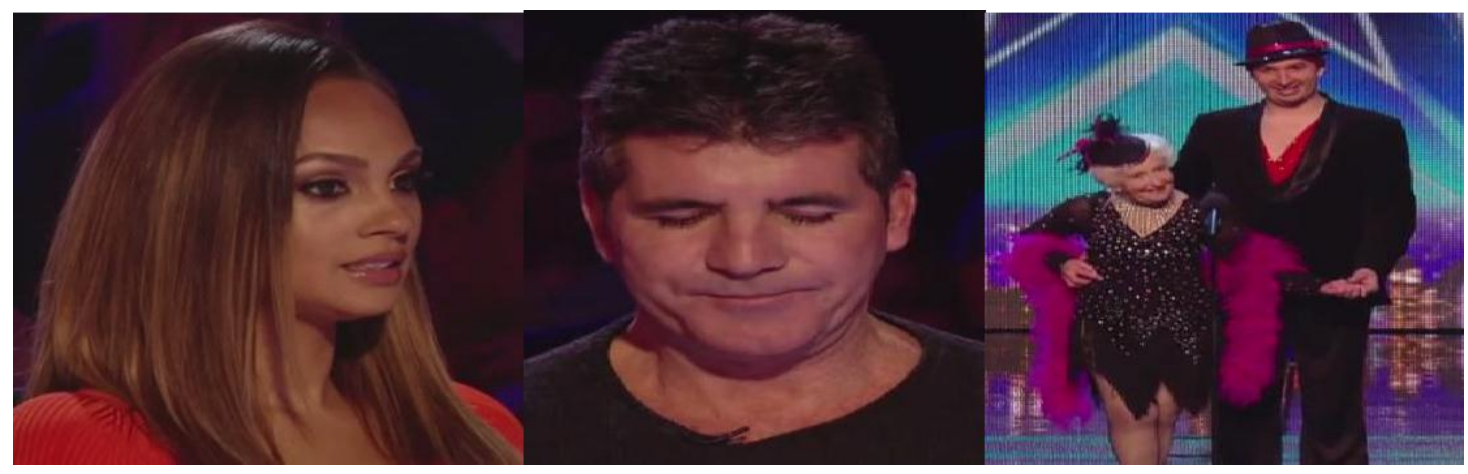

Fonte: https://www.youtube.com/results?search_query=Spectacular+Salsa+-+Paddy+++Nico++Electric+Ballroom+++Britain\%27s+Got+Talent+2014+-+YouTube

A expressão da primeira jurada levanta indício de certo incômodo ao se deparar com um casal tão peculiar. Já o segundo jurado sugere uma expressão de reprovação, pois desde o primeiro momento que esse casal entrou no palco, as feições dele e as falas demonstravam que ele não acreditava na possibilidade de tal casal produzir algo que valesse a pena assistir.

Parece que a imagem da senhora de 80 anos deixou transparecer no ideário desses/as jurados/as algo que se aproxima do frágil e do incapaz; percepção inerente ao pensamento moderno que, ainda com resquícios de seus princípios na contemporaneidade, atribui noções de inferioridade àqueles sujeitos que não se conformam com o padrão de beleza física, juventude e, em especial, de masculinidade o gênero norteador das relações de poder e saber em nossa sociedade. (GOELLNER, 2003; LOURO, 1997). Neste sentido, certo estranhamento parece emergir nos/as jurados/as pelo fato de ela estar com um par que possui, quem sabe, metade de sua idade.

A aversão demonstrada pelos jurados do referido programa pode ser explicada através do que Goellner (2003) afirma ser uma desestabilização e uma problematização dos significados culturais atribuídos aos corpos na sociedade. Conforme anteriormente explicitado, o corpo da mulher idosa recebeu, culturalmente, a representação de algo sem utilidade, uma vez que não apresenta mais a capacidade de reproduzir outro ser. Neste sentido, todas as outras atividades realizadas por este corpo, são avaliadas por este viés, de modo que, quando alguém ousa desestabilizar este "acordo social", há uma fragmentação de um padrão, de uma norma, e, como consequência, um estranhamento. 
A partir da desestabilização deste "acordo social", algumas reações são suscitadas frente aos "corpos que escapam" (LOURO, 2003). Assim, estes corpos passam a ser invisibilizados, ou mais que isso, considerados impossíveis, aqueles que devem ser escondidos, realocados na norma socialmente aceita e tornam-se excluídos, abjetos.

Richard Miskolci (2009) ao problematizar a experiência da abjeção descreve esse conceito como originário da Psicanálise que foi repensado à luz dos estudos queer principalmente na perspectiva butleriana. Refere-se a um sentimento de repulsa ou horror manifestado em relação a um fenômeno, sujeito ou grupo interpretado como "poluidor ou impuro", "contaminador e nauseante", portanto, temido, sendo alvo de injúria, "objeto de medo", geralmente interpretado pela coletividade como ameaça ao bom funcionamento social e político.

Nesse processo, aqueles/as que não se enquadram às normas sociais, nomeadamente às imposições de construção do gênero, sofrem da insignificância atribuída aos seus direitos à condição humana, em que a materialidade de suas vidas é tida como pouco importante, levados/as a se situarem em zonas invisíveis e inabitáveis da dimensão social. Neste primeiro momento da performance, não seriam essas zonas os lugares possíveis de existência daquela senhora na percepção daqueles/as jurados/as?

Com olhares que demonstram a surpresa e a incredibilidade e a abjeção com relação à performance executada por aquela senhora, por aquele corpo, os préjulgamentos em relação ao casal citado continuam. Um dos/as jurados/as logo de início votou pela eliminação da dupla, pois a performance dos dois iniciou-se de maneira lenta e regrada. O rosto demonstrando tédio era nítido em sua face, assim como, em reações capturadas nos/as expectadores/as da plateia. O jurado chegou a bocejar.

$2^{\mathrm{a}}$ Imagem retirada do vídeo objeto deste estudo.

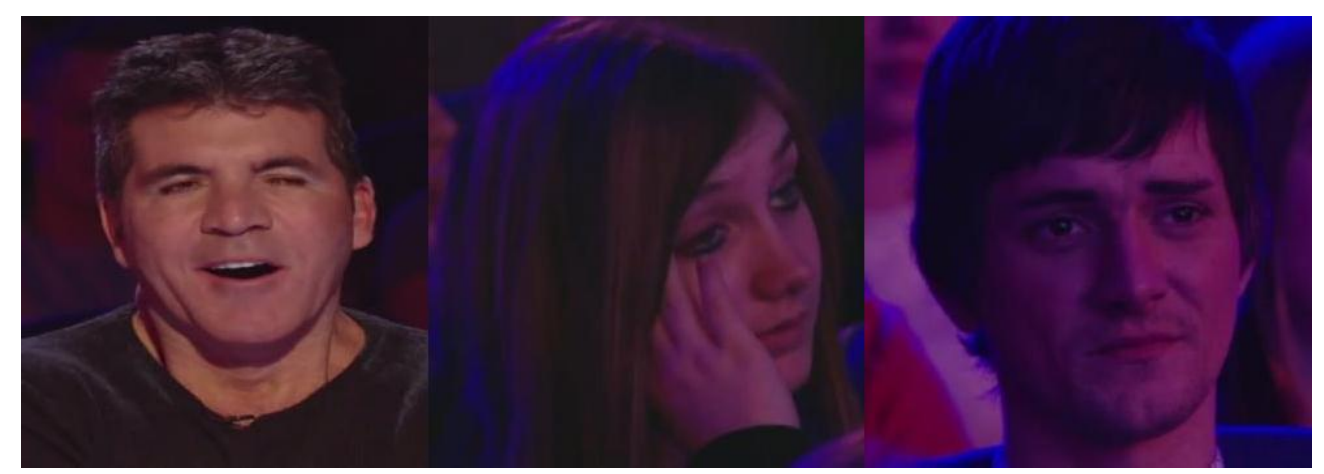

Fonte: https://www.youtube.com/results?search_query=Spectacular+Salsa+-+Paddy+++Nico++Electric+Ballroom+++Britain\%27s+Got+Talent+2014+-+YouTube 
As imagens capturadas servem para ilustrar como esses programas de calouros mostram a todo o momento os sentimentos/reações dos que ali estão em relação ao que está sendo apresentado. Constantemente são feitas pequenas filmagens da plateia, assim como dos/as jurados/as. Tais recortes permitem que o/a espectador/a que não está no auditório onde ocorre a apresentação tenha contato com os sentimentos expressos nas feições das pessoas que ali estão. Isso permite maior interação entre todos/as que assistem a esses programas, mesmo que não estejam fisicamente próximos/as uns dos/as outros/as.

Dessa forma, mesmo ausentes naquele período de tempo em que a apresentação foi realizada, quem assiste posteriormente ao vídeo pode verificar que a partir do momento que aparecem imagens da senhora sendo erguida ou conduzida em poses acrobáticas, instantaneamente, transformam-se as expressões faciais dos/as que ali estavam: do tédio à surpresa.

$3^{\text {a }}$ Imagem retirada do vídeo objeto deste estudo.

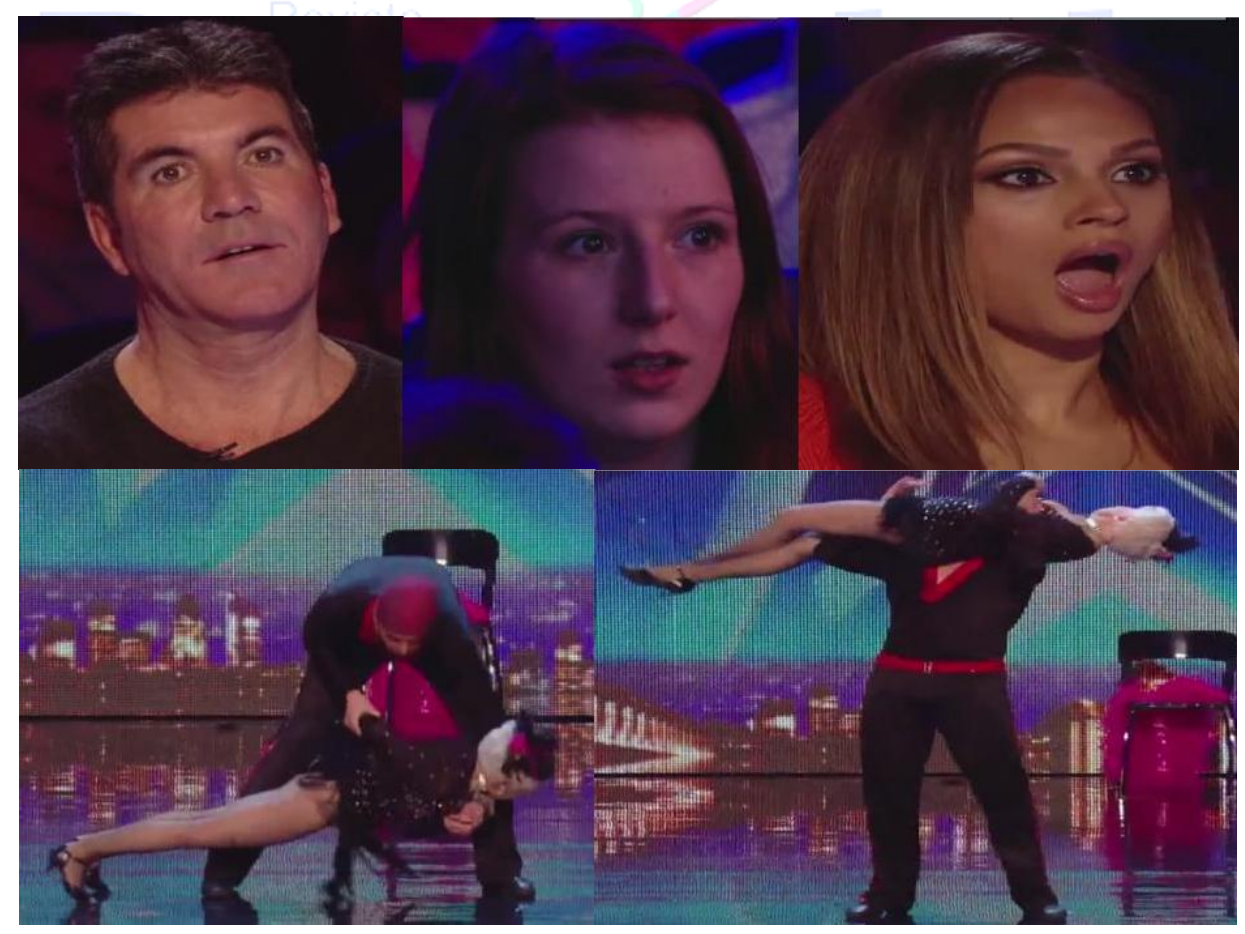

Fonte: https://www.youtube.com/results?search_query=Spectacular+Salsa+-+Paddy+++Nico++Electric+Ballroom+++Britain\%27s+Got+Talent+2014+-+YouTube

Nota-se que a expressão dos/as jurados/as muda radicalmente. A partir do momento em que a música da apresentação torna-se algo dinâmico com a realização de 
inúmeros movimentos acrobáticos, são realizados vários flashes da reação facial da plateia e dos/as jurados/as. Algumas expressões/reações beiravam a histeria. Tal fato reforça a ideia de que muitos/as daqueles/as que assistiam a apresentação do casal em questão não acreditavam que tal dupla pudesse fazer algo da magnitude do que foi apresentado.

Segundo Giuliano Andreoli (2010, p. 108), a dança, e também outras práticas sociais, podem ser constituídas pelos discursos e representações que fundamentam e dão sentido à vida social. "Por utilizar o corpo como parte principal da sua mensagem estética, a dança está muito fortemente implicada nos processos de linguagem que operam na construção cultural do corpo.”

Sendo assim, o que se espera do corpo de uma idosa, fundamentado nos discursos presentes na sociedade ocidental, é algo submisso, suave, focado em atividades como tricô e crochê, não uma performance acrobática que denotava força e destreza. Em relação a esses adjetivos, percebe-se que eles são mais utilizados para qualificar o "masculino". Segundo Tubert (1996) citado por Andreoli (2010, p. 110) o feminino normalmente remete a outros adjetivos; com isso, em

culturas ocidentais modernas, a feminilidade que é normalmente identificada como estando relacionada à capacidade reprodutora e à maternidade. Inúmeras práticas discursivas nomearam e descreveram a feminilidade desse modo, ao longo da história, como uma forma de ser reduzida apenas a essa função biológica (ANDREOLI, 2010, p. 110).

Pode-se afirmar, com base no exposto até aqui e nos escritos de Foucault (1988), que os processos de racionalização do corpo e da sexualidade da mulher passam por relações de poder e por um conjunto de saberes e discursos que irão demarcar o corpo feminino como patologizado, desviante e histérico; principalmente aqueles corpos que não se adequem aos papeis sociais a eles impostos pela sociedade, como é o caso da senhora que se apresenta em um programa de talentos, com um homem mais jovem, roupas "mais ousadas" e uma performance que, culturalmente não é considerada conveniente à sua idade. 


\section{Dispositivos que educam: Possibilidades do debate sobre gênero e desdobramentos interseccionais na escola}

Considerando as reflexões anteriormente postas, o vídeo objeto do presente trabalho pode servir como instrumento para quebrar com classificações relacionadas ao gênero e também a idade das pessoas. Podemos utilizá-lo como instrumentos para a discussão de inúmeras questões como: dança, o corpo idoso, possibilidades corporais, preconceitos em relação ao/à idoso/a, entre outras. Assuntos diversos podem ser abordados, problematizados buscando assim, a desmistificação de determinados "pré" conceitos existentes no mundo que habitamos.

Podemos, inclusive, trazer essas reflexões para o ambiente escolar usando um meio de comunicação que cada vez mais está presente na vida dos estudantes - a internet. Cria-se assim a possibilidade de se trabalhar com a reflexão de que os limites do corpo não se dão pelo olhar do outro. Podemos ir além. Ir além dos preconceitos, além das limitações, além de uma sociedade que julga, discrimina e exclui. A internet é algo de tamanha importância na sociedade atual, que não podemos deixar de usá-la como um instrumento educativo.

Enxergamos, dessa maneira, a partir das reflexões feitas no decorrer desse ensaio que o episódio traz à tona as fragilidades escondidas por detrás das concepções históricas, sociais e culturalmente construídas e ensinadas em relação aos lugares a serem ocupados e os papeis a serem assumidos por homens e mulheres que consagram a prevalência do primeiro em detrimento do segundo.

No trajeto dessas inquietações, nos questionamos sobre quais corpo(s) são autorizados dançar? O que uma senhora com um jovem mobiliza à primeira vista? Um rompimento da noção de que corpos idosos não têm mais capacidade, não apresentam mais a energia necessária para atividades que demandem agilidade, equilíbrio e força? Ou, para além disso, a noção de que estes corpos não servem mais para serem admirados, não têm mais potência e possibilidade de reprodução, portanto "não servem"? Ou, a forte compreensão no imaginário social de que corpos velhos não merecem viver? Ou são incapazes, abjetos, conforme conceituado por Miskolci (2012).

Nesse contexto, é importante ampliarmos as discussões e possibilidades das Tecnologias de Informação e Comunicação (TIC's) e dos diferentes artefatos culturais como meios para proporcionar aprendizagens e potentes discussões acerca do gênero, 
do fator geracional e de outros atravessamentos presentes na constituição identitária dos sujeitos, como classe social, raça e religião, por exemplo (LOURO, 1997).

Outro aspecto a ser discutido e ampliado com os alunos é o local da escola na constituição dos corpos possíveis e das representações acerca desses corpos e de seus diversos fatores acima elencados. É relevante desconstruirmos, junto com os alunos, paradigmas que instituem o gênero como algo fixo, estático e imutável, levando em consideração o papel da escola nessa (des) construção, ao considerar que ela (a escola) "(...) delimita espaços. Servindo-se de símbolos e códigos, ela afirma o que cada um pode (ou não pode) fazer (...) Informa o 'lugar' dos pequenos e dos grandes, dos meninos e das meninas"(LOURO, 1997, p. 68).

Desse modo, consideramos que artefatos culturais como filmes, programas como este aqui analisado, novelas, cinema, canções, etc. podem ser dispositivos úteis para desencadear reflexões, discussões, grupos de estudo e rodas de conversa que podem ampliar as noções sobre gênero, sexualidade, fator geracional, classe e diversos marcadores sociais da diferença, colocando também a escola como local onde as contradições existem e são produzidas e reproduzidas, tanto no sentido da manutenção dos padrões hegemônicos e socialmente impostos e que se tornam fator de exclusão, quanto como possibilidade de desconstrução de tais noções fixas e local potente para resistências e novas construções sociais para além daquelas já existentes.

\section{Conclusão}

Levando em consideração as reflexões traçadas neste trabalho, pode-se afirmar que o corpo é parte da construção identitária dos sujeitos e nele inscrevem-se práticas discursivas, que fazem com que este corpo, dentro das relações de saber e poder, adquira certas representações e papeis sociais que lhe conferem aceitabilidade ou abjeção. Essas noções balizam teoricamente o presente trabalho e são corroboradas por ele a partir das reflexões e análises propiciadas por meio das imagens, do encadeamento das cenas, das reações e discursos verbais e não-verbais proferidos pelos jurados e pela plateia diante da performance em questão.

A interseccionalidade presente nos estudos pós-críticos nos informa sobre categorias que se entrecruzam quando as reflexões sobre as identidades estão em jogo. No caso aqui analisado: corpo, gênero e fator geracional, de modo que compreendemos 
que o corpo feminino, e para além disso, o corpo da mulher idosa, é diferentemente compreendido e construído através das práticas discursivas.

O corpo da mulher carrega marcas. Quanto menos "dócil" for este corpo, mais marcas da abjeção ele terá. O corpo da mulher idosa deve, segundo os padrões estabelecidos pela sociedade e pela cultura, se manter no âmbito do lar, ser frágil e não ser mostrado. Trata-se de um corpo que não mais reproduz, não apresenta os encantos e mistérios da maternidade e, portanto, não é mais um corpo desejável.

Porém, segundo Foucault (1988, p. 91) "[...] lá onde há poder há resistência". Os corpos e as identidades não são pré-determinados, fixos, imóveis. Há aqueles que fragmentam a norma, desestabilizam a determinação dos lugares sociais nos quais seus corpos foram inscritos; corpos que deslizam e escapam, sendo múltiplos e mutantes. (LOURO, 2003)

Inspirados em Silvana Goellner (2003), entendemos que a performance artística da senhora com o "jovem" nos permite afirmar que pensar o corpo na e pela cultura é um caminho para desnaturalizá-lo, entendê-lo como processo histórico, distante de considerá-lo uma entidade a priori que lhe atribui lugares e vivências específicas. Com isso:

Um corpo não é apenas um corpo, é também o seu entorno. Mais do que um conjunto de músculos, ossos, vísceras, reflexos e sensações, o corpo é também a roupa e os acessórios que o adornam, as intervenções que nele se operam, a imagem que dele se produz, as máquinas que nele se acoplam, os sentidos que nele se incorporam, os silêncios que por ele falam, os vestígios que nele se exibem, a educação de seus gestos... enfim, é um sem limite de possibilidades sempre reinventadas e a serem descobertas. Não são, portanto, as semelhanças biológicas que o definem mas, fundamentalmente, os significados sociais e culturais que a ele se atribuem (GOELLNER, 2003, p. 29).

Contudo, cabe ressaltar que, numa perspectiva foucaultiana, os significados sociais e culturais atribuídos ao corpo podem ser resistidos em contraposição às relações de poder (FOUCAULT, 1988). A senhora dançarina parece desencadear esse processo, apresentando seu corpo como um fenômeno provisório, mutável e mutante que, mediante a cultura em que está inserido e os processos científicos e tecnológicos que o cercam, produz e reproduz diferentes representações e discursos. 


\section{Referências}

ANDREOLI, Giuliano Souza. Dança Gênero e Sexualidade: um olhar cultural.

Conjectura, v. 15, n.1, jan./abril. 2010.

BUTLER. Judith. Bodies that matter. On the Discursive Limits of "Sex". New York: Routledge, 1993

FERNANDES Maria das Graças Melo. Envelhecer na condição de mulher: algumas reflexões sobre corpo e sexualidade. Revista Ártemis 2009; 10: 164-170.Disponível em: http://www.biblionline.ufpb.br/ojs/index.php/artemis/article/view/11833/6887. Acesso em $1^{\circ}$ de março de 2015.

FOUCAULT. Michael. História da sexualidade: vontade de saber. Trad. Maria Thereza de Albuquerque e J. A. Guilhon Albuquerque. Rio de Janeiro: Edições Graal, 1988. $152 \mathrm{p}$.

FOUCAULT. Michael.Vigiar e punir: nascimento da prisão. 35 ed, Petrópilis: Vozes, 2008.

FURTADO, Ana Maria. Um corpo que pede sentido: um estudo psicanalítico sobre mulheres na menopausa. Rev. latinoam. psicopatol. fundam. [online]. 2001, vol.4, n.3, pp.27-37. Disponível em http://www.scielo.br/scielo.php?pid=S1415-

47142001000300027\&script=sci_abstract\&tlng=pt. Acesso em 17 Mar. de 2020.

GOELLNER, Silvana Vilodre. A produção cultural do corpo. In: LOURO, Guacira Lopes; FELIPE, Jane; GOELLNER, Silvana V. (Org.). Corpo, gênero e sexualidade: um debate contemporâneo na educação. 2. ed. Petrópolis, R J: Vozes, 2003, p. 28-40.

GUIMARÃES, Maria Eduarda Araújo. Globalização: corpo como campo de batalha. In: BUENO, Maria Lúcia e CASTRO, Ana Lúcia de. Corpo, território da cultura. São Paulo: Annablume, 2005.

HALL, Stuart. Cultura e Representação. Organização e Revisão Técnica: Arthur Ituassu; Tradução: Daniel Miranda e William Oliveira. - Rio de Janeiro: Ed. PUC-Rio: Apicuri, 2016.

HENNING, Carlos Eduardo. Interseccionalidade e pensamento feminista: As contribuições históricas e os debates contemporâneos acerca do entrelaçamento de marcadores sociais da diferença. Dossiê Desigualdades e

Interseccionalidades. Londrina, v. 20 n. 2, p. 97-128, jul./dez. 2015. Disponível em: http://www.uel.br/revistas/uel/index.php/mediacoes/article/view/22900/pdf\%27. Acesso em 18.05.2020.

IUNG, Eliane. Jordi; PORTUGAL, Cristina. Cultura visual e o cenário das narrativas e memórias. Cultura Visual, v. 1, n. 18, p. 27-39, 2012. Disponível em http://www.portalseer.ufba.br/index.php/rcvisual/article/viewFile/6241/4639. Acesso em 25.02.2015. 
LOURO, Guacira Lopes. Corpos que escapam. Estudos Feministas, v.4, 2003.

Disponível em

http://www.pibid.ufpr.br/pibid_new/uploads/edfisica2011/arquivo/243/corpos_que_esca pam.pdf. Acesso em 19.01.2014.

LOURO, Guacira Lopes. Gênero, sexualidade e educação: uma perspectiva pósestruturalista. Rio de Janeiro: Vozes, 1997.

MARTINS, Raimundo. Imagem, identidade e escola. Cultura Visual e Escola. ISSN 1982 - 0283. Ano XXI Boletim 09, p. 15-21, 2011.

MISKOLCI, Richard. Teoria queer: um aprendizado pelas diferenças. 2. ed. rev. e aum. Belo Horizonte: UFOP (Universidade Federal de Ouro Preto), 2012.

OLIVEIRA, Anderson José de, et al. O que representa ser idoso nos dias atuais? In Simpósio Mineiro da História da Educação Física. Anais. Juiz de Fora/MG, 2003. p. $319-324$

PARAÍSO, Marlucy Alves. Metodologias de pesquisas pós-críticas em educação e currículos: trajetórias, pressupostos, procedimentos e estratégias analíticas. In: MAYER, Dagmar E.; PARAÍZO, Marlucy A. (Org.) Metodologias de pesquisas póscríticas em educação. Belo Horizonte: Mazza Edições, 2012. p. 23-45.

PRADO FILHO, Kleber; TRISOTTO, Sabrina. O corpo problematizado de uma perspectiva histórico-política. Psicol. estud., Maringá , v. 13, n. 1, p. 115-121, Mar. 2008 . Disponível em: http://www.scielo.br/scielo.php?script=sci_arttext\&pid=S141373722008000100014\&lng=en\&nrm=iso. Accesso em 17 mar. 2020.

SARDELICH, Maria Emilia. Leitura de imagens e cultura visual: desenredando conceitos para a prática educativa. Educar em Revista, núm. 27, p. 203-219, 2006,

SILVA, Tomaz Tadeu da. Documentos de identidade: uma introdução às teorias do currículo. 2 ed, $9^{\mathrm{a}}$ reimp. - Belo Horizonte: Autêntica Editora, 2005.)

Spectacular Salsa - Paddy Nico - Electric Ballroom Britain's Got Talent 2014. Youtube. Disponível em: https://www.youtube.com/results?search_query=Spectacular+Salsa++ Paddy+++Nico+-+Electric+Ballroom+++Britain\%27s+Got+Talent+2014++YouTube. Acesso em 01.03.2019.

Susan Boyle's First Audition 'I Dreamed a Dream' | Britain's Got Talent. Youtube. Disponível em https://www.youtube.com/watch?v=yE1Lxw5ZyXk. Acesso em 16.05.2020

TOURINHO, Irene. As experiências do ver e ser visto na contemporaneidade: por que a escola deve lidar com isso?.Cultura Visual e Escola. ISSN 1982 - 0283. Ano XXI Boletim 09, p. 09-14, 2011.

VILHENA, Junia; NOVAES, Joana. O corpo e suas narrativas. Envelhecimento feminino e culto ao corpo. Psychologica, n. 50, p 85-96, 2009. 
Britain's Got Talent. Wikipedia. Disponível em:

https://pt.wikipedia.org/wiki/Britain\%27s_Got_Talent. Acesso em 16 de maio .2020.

Recebido em abril de 2020.

Aprovado em junho de 2020. 